\title{
Factors Influencing the Effective Leadership Succession Planning: Study on A Malaysian GLC
}

\section{Shamsulkahar Abdul Shukor and Suhaidah Hussain}

Faculty of Industrial Management, Universiti Malaysia Pahang, Lebuhraya Tun Razak, 26300 Gambang, Pahang, Malaysia

\section{Abstract}

Factors influencing effective Leadership Succession Planning (LSP) of one main Malaysian Government Linked Companies (GLC) becomes the focal scope of this research paper. The need to understand external factors, among others, on Malaysian economic policy itself, has a great influence on LSP program. It is not sufficient for the leaders in GLCs to only master their business operations knowhow. With the great interest to discover the actual practice of a successful GLC, researcher took this subject as this qualitative research is aimed to study the current factors and the gap

Corresponding Author: Shamsulkahar Abdul Shukor shamsulkahar@ump.my

Received: 5 August 2019 Accepted: 14 August 2019 Published: 18 August 2019

Publishing services provided by Knowledge

(c) Shamsulkahar Abdul Shukor and Suhaidah Hussain. This article is distributed under the terms of the Creative Commons Attribution License, which permits unrestricted use and redistribution provided that the original author and source are credited

Selection and Peer-review under the responsibility of the FGIC2019 Conference Committee. that is influencing the effectiveness of current LSP initiatives by a service-oriented of GLC, and to highlight some key critical factors as proposed in the literature. Factors influencing the effectiveness of LSP are also subject on the ability of the leaders to adopt to external changes particularly in the era of a borderless economic and faster rate of technology changes, and there are some differences among the industries and organizations, subject to the nature of the business and their stakeholders. Nevertheless, some important concept in LSP can be used as guidelines and practices be it from the primary data or the research literature. In view of this, the researcher is determined to conduct a qualitative study in meeting the research objectives and to answer the research questions. An interview with the Group Chief Executive Officer (CEO) of one GLC, who is the subject matter expert. The recording from the interview was transcribed and further analyzed using ATLAS.ti software. The findings evidence that there is the current practice of leadership succession planning in the company, anyhow there is a gap between the aspirations of the Group CEO and the availability of C-level replacement from within, and between the reality and the theories. Results of the findings identify the outcomes that need to be taken into action for a more effective LSP program. In the future, similar research approach can be conducted to other GLCs in order to analyze the similarities and complementary aspirations with regards to LSP.

Keywords: leadership succession planning, Malaysian government linked company.

\section{Introduction}

Leaders in any organizations may come and go, but the organizations itself need to continue to exist and grow, particularly business organizations whose existence is dependent on their business revenue. The leaders are being held responsible for 
leaders of business organizations including stakeholders and Board of Directors, must have the awareness and need to know how to best develop it across all C-levels (Csuite, also called C-level is commonly referred to high-ranking executive titles within business organization who are responsible for the organization's performance. $C$ refers to chief, which in this study is Chief Executive Officer, Chief Financial Officer, Chief Operating Officer and to some extent Chief Technology Officer, Chief Marketing Officer and others, subject to the size of the organization. It goes to the same for President, Senior/Vice Presidents or alike for some organizations.), in order for the organization to survive and thrive. Leadership Succession Planning (LSP) is a key processes in assessing and developing an organization's leadership talent (Lewis \& Heckman, 2006). Continuous performance of business organizations, which is much dependent on the strong leadership, becomes the focus of interest of various references by many. Findings by literature stated that transformational, well trained and proactive leadership influences organizational performance positively (Avey, Avolio, \& Luthans, 2011; Carmeli, Schaubroeck, \& Tishler, 2011; García-Morales, Jiménez-Barrionuevo, \& Gutiérrez-Gutiérrez, 2012). Besides the business operation knowhow, the C-level leaders of the business organizations should be able to manage the dynamism and complexity of business challenges mainly external factors. The leaders must be able to always updating their strategic business planning using measures such as PESTLE, which is developed to evaluate the impact of 'Political, Economic, Social, Technological, Environmental and Legal' factors (Rastogi \& Trivedi, 2016).

\subsection{Background of the Study}

Malaysian economic, to some extent, is partly moved and influenced by GovernmentLinked Companies (GLC) (GLCs are managed and supervised by the Government of Malaysia's strategic investment fund of, namely Khazanah Nasional Berhad. They are entrusted to undertake strategic investments on behalf of the nation and to hold and manage the commercial assets of the Government, (Khazanah, 2018)). Malaysian government, through its formed GLCs, acquire stakes in some Malaysian companies particularly those serving basic utilities, goods and services to the general public, in ensuring national aspirations, social needs and to ensure sustainability in facing global challenges are fulfilled (Centre for Public Policy Studies, 2006; Vietor, 2007; Beh, 2007). Malaysia's GLCs function as part of the government's strategic move and mechanism to better manage its economic performance, in ensuring balanced socioeconomic ingredients which include the fact of being a multi-racial nation, political factors, education, 
and social well-being factors. For a start, the researcher is interested in learning how LSP is practiced in one of the GLCs, by focusing on the effectiveness of the company's current LSP and what is the gap that exists between the current performance and the aspiration of its newly appointed Group Chief Executive.

\subsection{The Company}

Figure 1 shows the organization structure of the Company, to give an idea of how the Clevel is structured. The biggest shareholder of this organization is Khazanah Holdings, an investment company wholly owned by Malaysia Government through Finance Department, which is $33.2 \%$ of the total quantity of 1.66 billion shares, followed by another Malaysian Government wholly owned organization namely Employees Provident Fund which is $10.8 \%$.

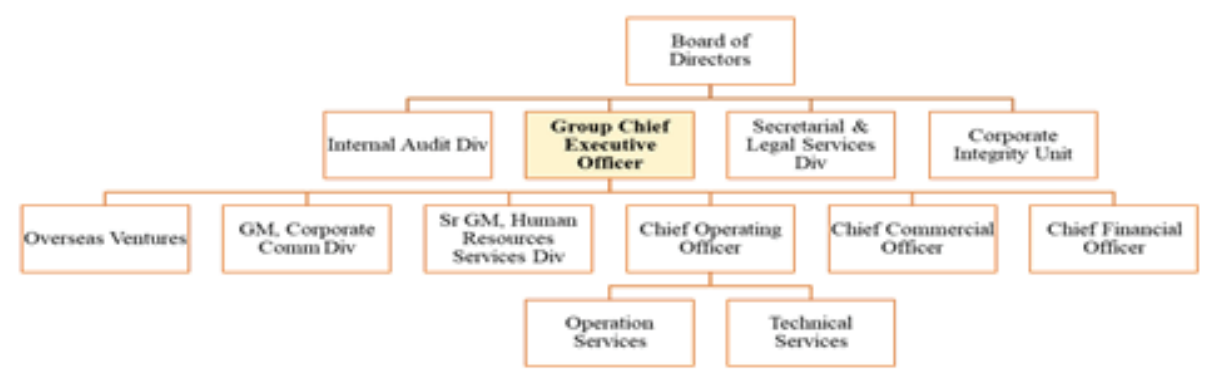

Figure 1: Organization Structure of the Company (Source: The Company's Website).

In order to meet the expectation of their main stakeholders, particularly the government through Khazanah Holdings, GLC leadership be it current or in future, to be filled with the right candidate who are trained and instituted a framework for investment decision making, that all investments and divestments having to go through several "decision gates," including the executive committee and a number of board members, which is composed of a mix of renowned private sector personalities and senior relevant government officials (Hayat, 2013).

\subsection{Situational Analysis and Challenges of GLCs}

Leaders of the GLC must ensure that their companies enjoy continuous excellent financial performance and shareholders value, which is the government, even though the Company does not have competitors. Poor LSP will cause inefficiency of company performance, which leads to some perception impact on government integrity and on its business viability. 
Malaysian Government own some percentage of ownership in the GLCs, and also has the final say on the appointment of GLC top management, through its investment arm Khazanah Holdings. Thirty six percent of the market capitalization of the Malaysian stock market in 2017 is owned by Khazanah, thus play a significant role in the development of the country's economy (Mokhtar, 2005).

Appointing candidates for the appointment of CEOs in GLCs to have to go through a stringent process. The government already has proper recruitment procedures and techniques in place, thus ensuring transparencies and accountability of the appointments (The SUN, 2017). Another aspect to be looked into is that political leaders must abide by their limit in the involvement in making some very important decisions. It is more significant to have greater decentralization in the GLC's decision making to achieve faster implementation and effectiveness even though it may cause dilution of the federal government power (Malaysia National Economic Advisory Council, 2008).

\subsection{Research Objectives}

The objectives of this paper are:

1. To learn the company's current practice of LSP

2. To identify LSP effectiveness factors

3. To identify the gap between reality and aspirations on LSP program by their leader.

\subsection{Research Questions}

Research questions are:

1. How does the Company carry out its current LSP strategies or program?

2. Why there is a gap between the expectation and the outcome of LSP, and how effective is it?

3. How will succession planning be able to prepare the next generation of CEO and general managers to be competent and able to function on the next higher level of management? 


\section{Literature Review}

Leadership succession planning (LSP) become an important subject need to be taken into account by the stakeholders and top management of any organization, when a replacement for C-levels is needed be it based on the planned or sudden requirement (Galagan, 2010; Bocatto, 2010). Developing employees to assume leadership role is very important for any organization's LSP which is pertinent tool in preparing for future changes in employee demographics (Calareso, 2013; Beheshtifar, 2012; Fink, 2011), and due to the fact that their companies have committed, dedicated and high-functioning trustees who work toward great outcomes for the plan (Brent, 2013).

\subsection{Existing LSP Sourcing Strategies}

Identifying and developing high potential internal employees becomes an integral task of organizational planning and performance (Risher, 2015; Yamkovenko \& Hatala, 2015). Competencies and skills of high potential managers of the future leaders are critical components of LSP where the process need to be assessed accordingly and continuously (Moradi, 2014; Hanson, 2013). It is an important business sense for having a list of internal candidates from time to time for the talent pipeline (Saratun, 2016). The company should be willing to invest in systematic and synergistic practices for sourcing high potential internal talent through LSP (Cho \& Poister, 2014).

When we talk about coaching, constant engagement in an active leadership development planning process with those high-potential managers brings about motivated and trust their higher-level management particularly their mentors with their career progression (Saratun, 2016). Top management needs to leverage it to motivate and develop future leaders, and executive coaching is one of the most effective methods for developing high potential internal managers for multiple job levels and promotions (Chung, 2012).

\subsection{Addressing Gap in the Current LSP Implementation}

Leadership skills gap among the immediate subordinates to the C-levels can be reduced and addressed through formal coaching and mentoring, series of relevant training, executive interviews (Stewart, 2016). While addressing development gaps and improving the connection between performance and potential, relationship building is fostered and nurtured and can be developed during the one-to-one session, and along the 
way could be a transactional exchange of information between the top management and those high potential employees (Allio, 2012). Similarly multigenerational workforce will lead to gaining the opportunities to take on special assignments to sharpen skills and wider exposure (Quintana, 2014), and meeting the needs of them to enrich new skills and capabilities and gain exposure to other leaders across the organization via cross-training and talent awareness session (Dewah \& Mutula, 2014).

Remediation of their learning gaps via new skills exposure and development, improves performance, where they will become more promotable employees thus creating a win-win culture and preparing LSP actual talent for the company (Blattner, 2015) and cultivating leadership skills, makes employees from degrees of potential to emerge and shape as leaders (Jing \& Avery, 2016). Bi-directional relationship between potentials and top management would be able to reduce leadership gaps as they are to be accountable for sharpening, training, and development of qualified high-potential managers through succession planning (Moradi, 2014).

\subsection{Meeting Organizational Needs}

The capabilities of high-potential employees and leaders by having replacement planning strategies become a norm when it is tied up with the winning culture (Sheth, 2016). Cultivating replacement planning strategy where high-potential employees can be generated, is also become another winning culture that benefits the organization (Nold, 2016).

LSP needs to have the preparation for the leaders to accomplish the organizational needs, to strive to accomplish organizational targets and goals (Metcalfe \& Metcalfe, 2013). The behavior of constant communication is also important to be cultured between leaders and high-potential employees linked, and drives to the business needs affect its efficiencies and effectiveness, leads towards win-win workplace climate (Stumpf, JR, Ehr, \& Dam, 2016; Blattner, 2015; Quintana, 2014).

Business organizations must keep alert and be prepared in making operational decisions when it comes to external factors as well. Besides political changes as happened in Malaysia as happened in the recent General Election in May 2018 as discussed in Chapter 1, their potential leaders need to have pro-active ability to face the globalization openness market, disruption of technologies, and workforce. Rate of changes and external influences is unpredictable, urging the need for organizational agility that influences internal operation disruption (Bass, 2008; Ariss, Cascio, \& Paauwe, 2014; Greenhalgh \& Jantti, 2012). 


\section{Methodology}

\subsection{Research Design}

The research design used for this study will apply qualitative research. It is usually considered as inductive approach, with the underlying assumptions being that reality is a social construct where it is difficult, complex and interwoven to measure its variables, that there is a primacy of subject matter and that the collected data shall consist of insiders' point of view and knowledge (Rovai, Baker, \& Ponton, 2014), which provide a content and context-rich breadth of information is current and practical although subjective (Tracy, 2013), aimed at instead of the surface description of a large sample of a population, it is aimed at achieving deep understanding of a specific organization or event. Qualitative has five areas, namely case study, ethnography study, phenomenological study, grounded theory study, and content analysis (Bhawna \& Gobind, 2015).

Besides the above, researcher applies exploratory type of research which is the method to clarify and define the nature of the problem in the research, as opposed to descriptive research which is to describe characteristics of the studied population or phenomenon, and causal research is carried out to study the link of cause-and-effect relationships among variables post-identification of the research problem (Zikmund, Carr, \& Griffin, 2013). Conceptual Framework

The following diagram, as in Figure 2 illustrates the conceptual framework for the study, demonstrates three independent variables are identified and classified in answering the objectives and questions that testify the scope of the study's topic.

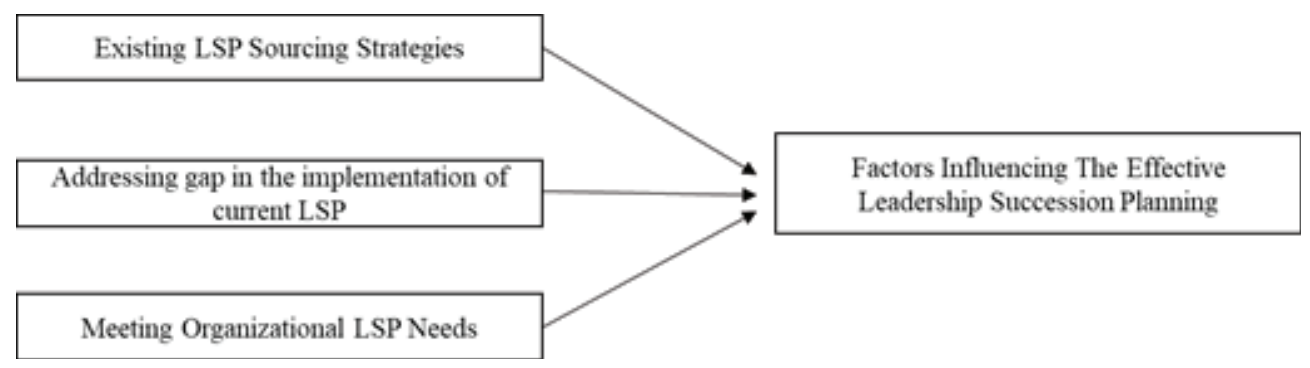

Figure 2: Conceptual Framework (Source: Authors' own work).

\subsubsection{Data Collection}

The interview was conducted in this context can be understood as the nature of qualitative research. Types of the interview are structured interviews, unstructured 
interviews, and semi-structured interviews (Haron, Khalid, Ganesan, \& Fernando, 2017; Neale, 2006).

In this study, an individual interview was carried out. The outcome of the interview is very informative and contains relevant data required for the study. The Group Chief Executive Officer (CEO) with a manpower strength of approximately 10,000, is the participant for this study. $\mathrm{He}$ is the subject matter expert and the right person to fulfill the objectives of research questions adequately. The outcome and analysis cannot be generalized, and anyhow the findings served as a very reliable reference.

\subsubsection{Data Analysis}

'Themes' are identified at the beginning of the process and are classified in qualitative research, and are used as an element, descriptor, attribute, and concept. Themes provide a path to smoothen researchers to analyze for the answers of the study questions in a more structured manner, in a way as an implicit topic that organizes a group of repeating or relevant ideas accordingly (Ryan \& Bernard, 2003). Having themes is with the purpose that the research participants' subjective meanings and social reality are linked, structured and appropriately conveyed in the research report (Horsburgh, 2003), as data alone may not merely provide meaning and answers to the questions. Themes are formed to convey the meanings of data analysis. So, themes are constituted by a group of codes that have a common point of references and answers to the research questions based on the data collected, which is the interview and from literature review, and has a high level of generality that unifies ideas pertaining to the subject of inquiry (Bradley, Curry, \& Devers, 2007).

An interview session with the respondent on 6 April 2019 in Shah Alam, Selangor, on one to one and face to face session, was the beginning of the data gathering process. It went smoothly and was recorded for 23 minutes and 34 seconds. The audio record was sent to an online system called 'TranscribeMe! for transcribing the conversation record into text form. The full transcribed text is uploaded into ATLAS.ti application, as shown in Figure 3. Researcher opens the file in the system, go through the text, and select one text passage (quotation) to another passage, which is relevant to the research questions. The researcher needs to define keywords for each passage and grouped them into themes and further followed by coding, as illustrated in Figure 4. 


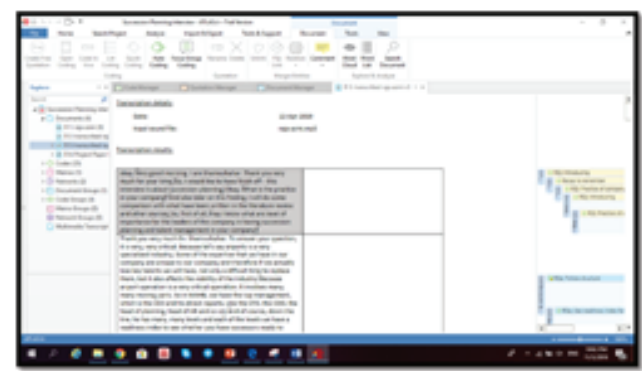

Figure 3: The Transcribed Voice Recording Document In The Software (Source: Author's own work in the software).

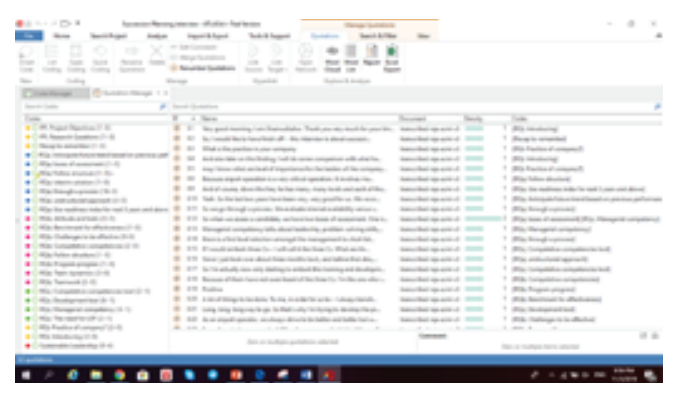

Figure 4: List of Codes (Source: Author's some timework in the software).

\subsubsection{Significant Statement (Quotations)}

The key component in qualitative data analysis is compiling and assigning quotations or statements to the respective group of Codes, by using ATLAS.ti that can use and process discrete interaction with text or multimedia segments. Researcher and analysts can understand the full context of every single document with the help of those quotations, before considering categories that cut across the entire research project.

\subsubsection{Reliability of Research Instrument}

Initial research questions and objectives have been commented by two senior lecturers of UMP. Further to that, the interview questions were reviewed by two other senior lecturers.

Feedback on the summary of research objectives, interview questions, and framework by the participants was also taken into account during the presentation session in the International Conference on Business Intelligence, Industrial Engineering \& Management (ICBIIEM) 2018 on 11 December 2018.

The interview voice recording was sent for transcription to an American based Transcribe. Me! Software as shown in Figure 5, with minor manual edit on the unclear pronunciation and usage of Malay language. 


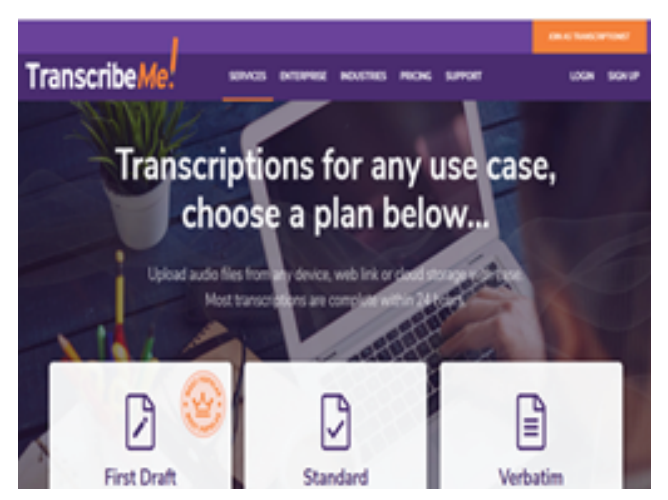

Figure 5: Transcribe.Me! software (Source: TranscribeMe!).

The use of ATLAS.ti application for analyzing and processing the qualitative gathered data with direct guidance by a certified ATLAS.ti trainer.

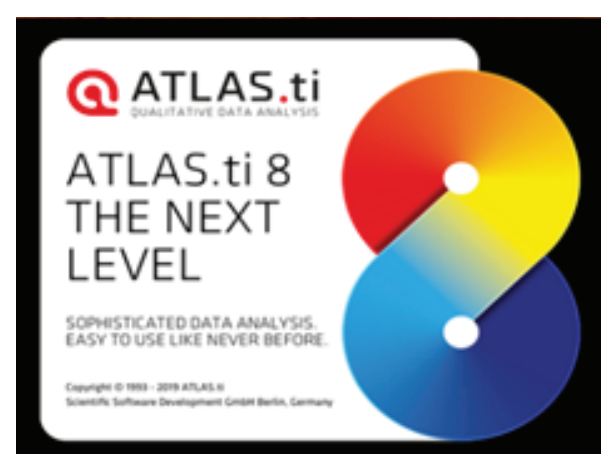

Figure 6: ATLAS.ti software (Source: ATLAS.ti).

\section{Results}

\subsection{Formation of Themes and Codes}

The main data collection in this Leadership Succession Planning is rooted in the interview with Group Chief Executive Officer, who is the lead of the company's business and operations. The researcher sought and presented the findings based on the questions (which were pointed based on the research objectives), grouped the data that answered the questions into themes and further into its respective codes, as shown in the table below.

There are two documents uploaded into ATLAS.ti for analysis, which are the transcribed interview document, and Literature Review of the research is also uploaded. The table shows how many quotations are there in each Codes. 'Through a Process' code scores the highest number in both Transcribed Voice Text and Literature Review, followed by 'Challenges to be effective.' 
TABLE 1: Themes and Codes (Source: Author's own work in the software).

\begin{tabular}{|c|c|c|c|c|c|}
\hline \multirow[b]{2}{*}{ Themes } & \multirow[b]{2}{*}{ Codes } & \multicolumn{2}{|c|}{ Number of } & \multicolumn{2}{|c|}{ Totals } \\
\hline & & 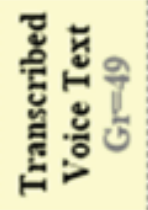 & 飬总 & 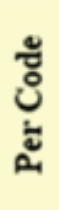 & 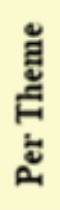 \\
\hline \multirow{7}{*}{ 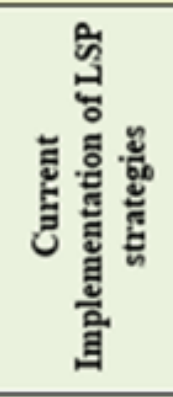 } & $\begin{array}{l}\text { - RQa; Anticipate future trend based on } \\
\text { previous performance. } \mathrm{Gr}=1\end{array}$ & 1 & 0 & 1 & \multirow{7}{*}{24} \\
\hline & - RQa; bases of assessment. Gr=1 & 1 & 0 & 1 & \\
\hline & - RQa; Follow structure. Gr=1 & 1 & 0 & 1 & \\
\hline & - RQa; interim solution. $\mathrm{Gr}=1$ & 1 & 0 & 1 & \\
\hline & - RQa: through a process. Gr=16 & 12 & 4 & 16 & \\
\hline & - RQa; unstructured approach. Gr=3 & 3 & 0 & 3 & \\
\hline & $\begin{array}{l}-\mathrm{RQa} \text {; Use readiness index for next } 3 \text { years } \\
\text { and above. Gr=1 }\end{array}$ & 1 & 0 & 1 & \\
\hline \multirow{8}{*}{ 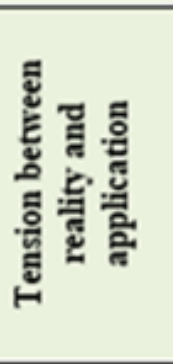 } & - $\mathrm{RQb} ;$ Attitude and traits. $\mathrm{Gr}=5$ & 3 & 2 & 5 & \multirow{8}{*}{23} \\
\hline & - RQb; Benchmark for effectiveness. Gr=1 & 1 & 0 & 1 & \\
\hline & - RQb; Challenges to be effective. $\mathrm{Gr}=9$ & 9 & 0 & 9 & \\
\hline & - $\mathrm{RQb}$; Competitive competencies. Gr=2 & 1 & 1 & 2 & \\
\hline & - RQb; Follow structure. $\mathrm{Gr}=1$ & 1 & 0 & 1 & \\
\hline & - $\mathrm{RQb}$; Program progress. Gr=1 & 1 & 0 & 1 & \\
\hline & - RQb; Team dynamics. Gr=2 & 1 & 1 & 2 & \\
\hline & - RQb; Teamwork. Gr=2 & 2 & 0 & 2 & \\
\hline \multirow{4}{*}{ 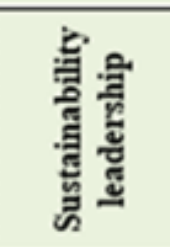 } & - RQc; Competitive competencies tool. $\mathrm{Gr}=2$ & 2 & 0 & 2 & \multirow{4}{*}{14} \\
\hline & - RQc; Development tool. Gr=6 & 2 & 4 & 6 & \\
\hline & - RQc; Managerial competency. Gr=4 & 3 & 1 & 4 & \\
\hline & - RQc; The need for LSP. Gr=2 & 2 & 0 & 2 & \\
\hline \multicolumn{2}{|l|}{ Totals } & 48 & 13 & 61 & 61 \\
\hline
\end{tabular}

\subsubsection{Data Analysis Network Diagram}

Representation and exploration of conceptual structures are simplified and summarized using network illustration used in ATLAS.ti. Network diagram adds a heuristic 'rightbrain' approach is used in qualitative analysis. A psychologist and Nobel Prize winner, Robert W.Sperry, according to research in the 1960s, suggests that the right brain is more intuitive and visual, and also connected to imagination, intuition, holistic thinking, rhythm, art and feelings visualization (Pietrangelo, 2017). The researcher can use the structural properties of code-networks to enhance the quotations retrieval, besides using the network for the visual design of theoretical models and 'mind-mapping,' for a summary view on the overall link of the themes, codes, and quotation by the readers.

Each of the research themes which constitute part of the research objectives and questions, and list of codes that constituted each of the themes, is summarized in the 


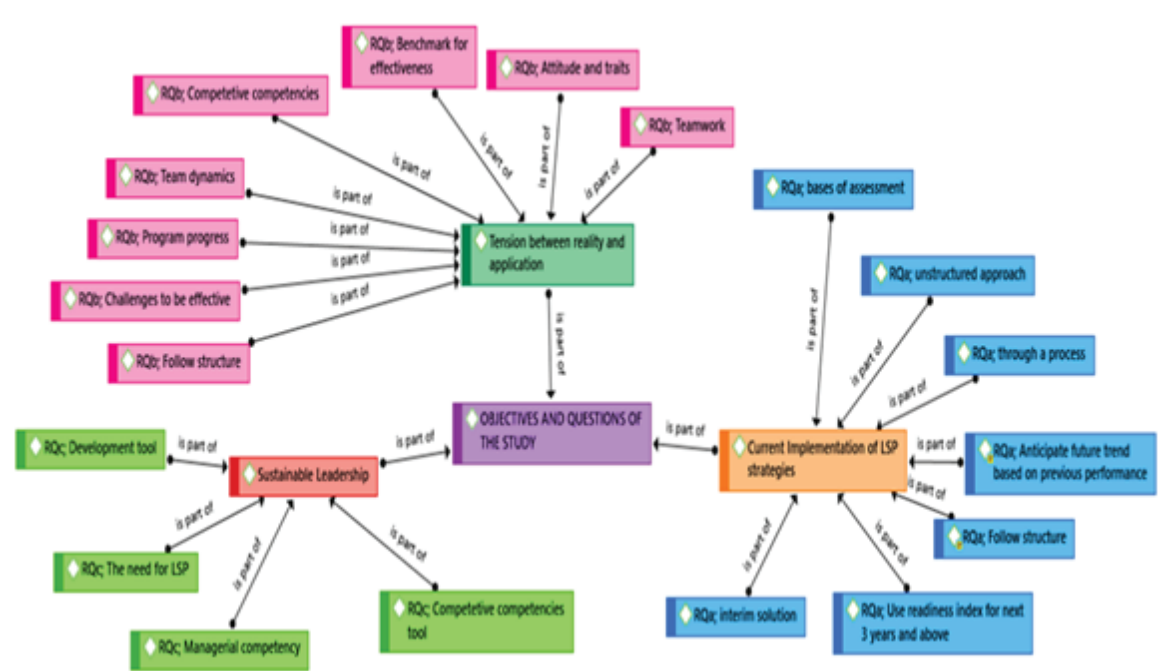

Figure 7: Network Diagram of Themes and Codes (Source: Author's own work in the software).

network diagram, as shown in Figure 7. Three themes are identified in answering the research questions, (i) Current Implementation of LSP Strategies, (ii) Tension between Reality and Application, and (iii) Sustainable Leadership. Codes are assigned in each of the themes. Some codes are relevant to more than one theme.

\subsection{Theme: Current Implementation of SLP Strategies}

An overview on 'Current Implementation of SLP Strategies' theme and those codes linked to it is shown in the network diagram in Figure 8, which further connected by a list of selected quotation summary connected to each of the relevant code, with the time that respective statement was stated during the interview recording.

\subsection{Theme: Tension between reality and application}

'Tension between reality and application' theme and those codes linked to it, is illustrated by the network diagram as shown in Figure 9, followed by a list of selected quotation summary connected to each of the relevant code, with the time that respective statement was stated during the interview recording.

\subsection{Theme: Sustainability Leadership}

'Sustainability leadership' theme and those codes linked to it, is illustrated by the network diagram Figure 10 below, and further connected by a list of selected quotation 


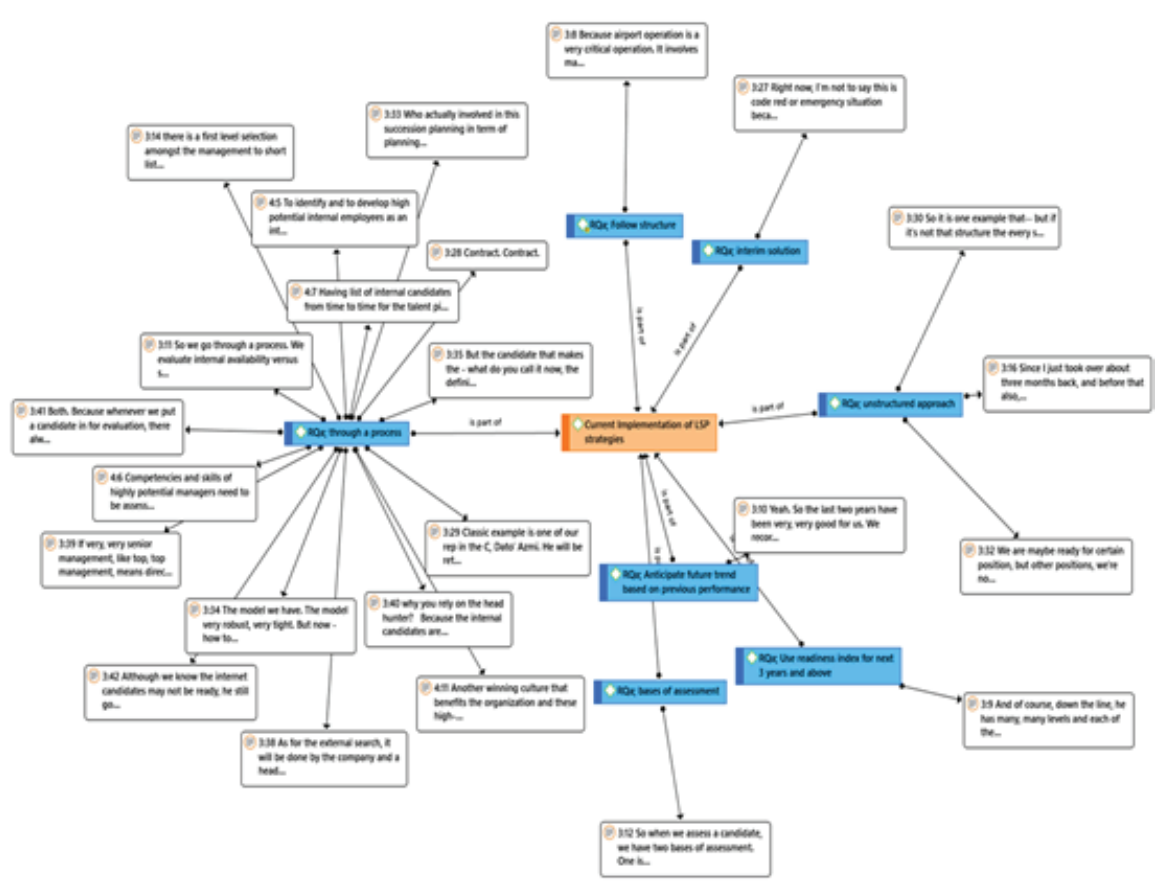

Figure 8: Current Implementation of SLP Strategies (Source: Author's own work in the software).

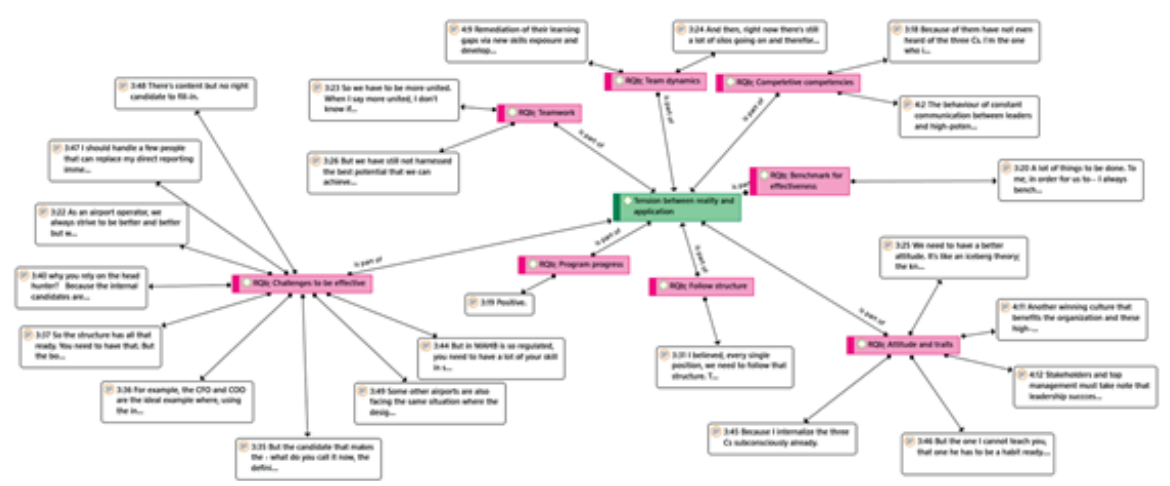

Figure 9: Tension Between Reality And Application (Source: Author's own work in the software).

summary which connected to each of the relevant code, with the time that respective statement was stated during the interview recording.

\section{Discussion}

The study on the factors influencing the effective leadership succession planning on a Malaysian GLC covers three main areas which are known as themes. The researcher highlighted the importance of leadership succession planning, particularly on the external factors that have an impact on the company's business direction and operation. The world is currently facing the dynamism of technologies and applications, and the political climates such as a change in the ruling government, the impact of any major incidents like earthquake and many others, potential leaders of a business company must be 


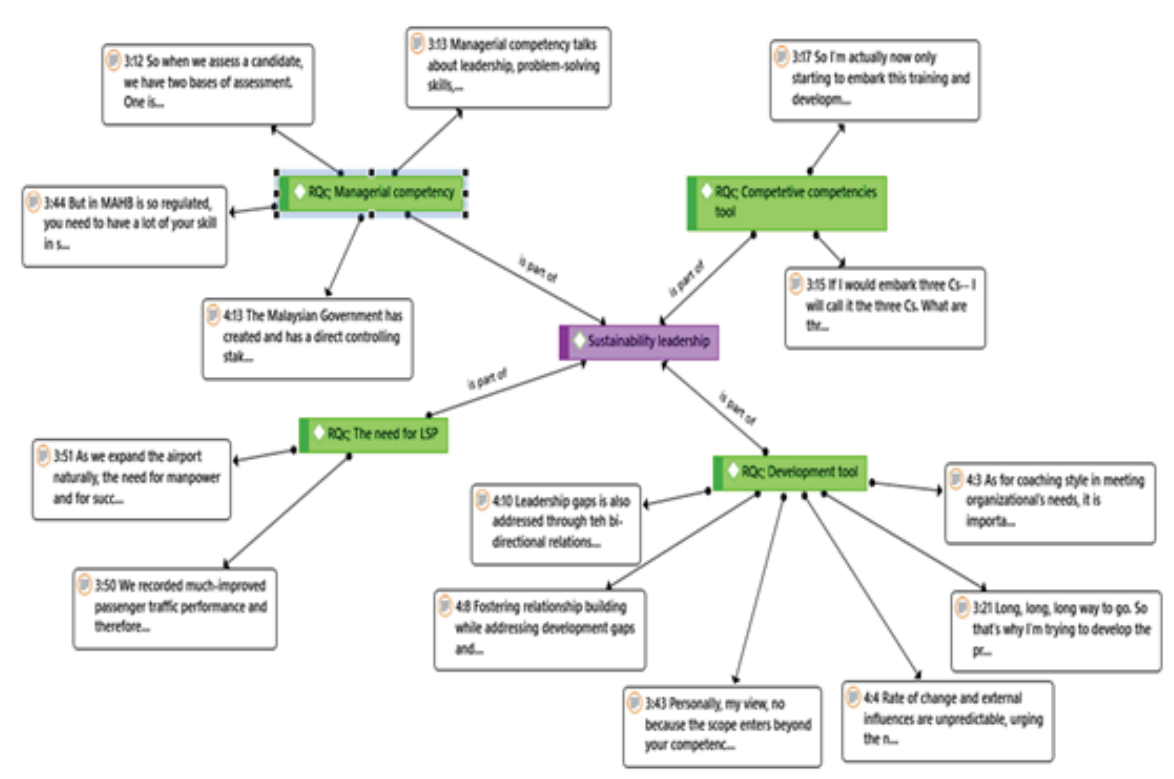

Figure 10: Sustainability Leadership (Source: Author's own work in the software).

quality of making a right and fast decisions. Within the time constraint in conducting the study, the researcher managed to dig some valuable information that is beneficial theoretically (academic implication) and practically (managerial implication).

It is important to understand that the requirement for providing effective LSP in ensuring leadership quality and capability keeps changing in responding to the macroeconomic factors, the research on LSP needs to be carried out from time to time. Theories and literature might be debatable after some time. The researcher conducted this study as to give some ideas on the changes in the leadership aspects, for the academicians to blend the learning module to meet the industrial needs.

The discussions are based on the overall analysis of data, as in the Attachment I.

\section{Limitation of the Study}

The researcher had experienced some limitations in conducting the study which has an impact on the level of accuracy of the study's output or conclusion. The most critical limitation in conducting any study is time and references. Time constraint for the researcher to comply conduct the study within a semester, being a part-time student. Time constraint is also experienced in scheduling for the interview with the respondent, due to his hectic schedule to spend time for the interview.

Confidentiality of some operational information also contributes towards the limitation. Business organizations, like the Government-Linked Companies are not willing to share their approach due to the highly competitive environment globally. Another 
limitation is, there is a very minimal number of previous studies on LSP topic, as the result of the difficulties in getting information. This will limit the study on the gap to be analyzed. Researcher proceeded with the study despite those limitations, since LSP topic is very important for any organizations, particularly those who have a direct interest by the government. The researcher had also spent some extra effort and time to learn a new application system for data analysis.

\section{Recommendation for Future Study}

As highlighted in the Implication section earlier, output or implication of the study has given valuable information to the LSP subject. Thus, it gives greater impactful information if a further and thorough study to be carried out, such as y having more respondents particularly C-levels, since they are the subject matter expert and have vast experiences in ensuring their organization to progress well and to meet stakeholders expectations. At the same time, a mixed research method can be conducted as well in order to come out with a more practical and accurate leadership succession planning strategies.

The combination of the above recommendations will yield triangulation results that can give greater understanding and analysis on the shortcomings or challenges in having a comprehensive LSP and to sustain the company's performance in the long run. As this is a qualitative study, the findings cannot be generalized into other industry or organization. More study needs to be to other organization. To provide a matched analysis, future researchers can conduct research on other Government-Linked Companies as well. Even though the nature of business might be different among GLCs, C-level candidates share about the same competencies and skills in managing their organizations and to remain competitive.

\section{Conclusion and Implications}

Referring to section Research Aims and Objectives earlier, the objectives of this study have been achieved through the qualitative research methods as described in chapter Research Methodology. Interview and literature had been compiled and analyzed, as stated in Section Analysis, is done using ATLAS.ti analysis tool to sort out and to arrange the quotations or excerpt those relevant data into themes and codes. The outcome of the findings and analysis is obtained using this system.

The success of the study is contributed by the interview participant, who is chosen by the researcher due to the proven track record of performance and from a very dynamic 
organization, and at the same time, has to comply with the government strict policy, so that the interviewee's experiences and his way forward strategies can be learned by other practitioners, academicians and himself. It is beneficial to learn the challenges he has been facing, the areas that need to be focused, and how he plan to overcome those shortcomings.

Conclusively, the study has given a good beginning exposure for further researches to come out with the realistic strategy sharing and theories that can be benefited by any organization, in order to ensure there are an effective LSP and continuous performance growth. The subject of this study will always subject to revision and improvement in lieu of the development of the technologies, borderless world, business dynamism, and complexity of the overall system.

\section{Acknowledgement}

I wish to sincerely thanks to my research supervisor, Dr. Suhaidah Binti Hussain from the Faculty of Industrial Management, Universiti Malaysia Pahang, for the valuable guidance, expertise, and knowledge sharing and encouragement throughout the research. She is very supportive who always ensure the progress of conducting and writing this research. She has introduced and recommended me to use ATLAS.ti software to analyze my collected qualitative data effectively. I would like to take this opportunity to express my warm thanks to my family for their understanding and moral support particularly it was very time consuming, to manage the time for family, work and research. I sincerely appreciate their unceasing encouragement, support, and attention that lead me toward the success of this research.

\section{Funding}

I would like to express my sincere appreciation to the Bank Rakyat for funding my participation in the presentation of my research paper in this FGIC 2nd Conference on Governance \& Integrity.

\section{ATTACHMENT |}

HOW DATA IS ANALYSED 


\title{
Theme: Current Implementation of LSP strategies.
}

\author{
Quotations from the interview in this sub-section are responding to the Research
} Question: How does the Company carry out their current LSP strategies or program? Each selected quotation or statement is linked to the research objectives as elaborated in the Interpretive Meaning column in Table 2 below.

TABLE 2: Significant Statement and Meaning from Current Implementation of LSP Strategies Theme.

Significant statement
Current Implementation
very good for us. We recorded much-improved
passenger traffic performance and therefore
that resulted in us earning a great profitability
and we anticipate this trend to continue in the
next few years. So far year-on-year we have
been recording growth. There is no
year-on-year decline in passenger traffic
volume hence the results have been very, very
encouraging. Yeah. It's been positive".
Document Source: Transcribed Voice Text
(3:10).

- "So when we assess a candidate, we have two bases of assessment. One is the technical competency and the other one is the managerial competency". Document Source: Transcribed Voice Text (3:12).

- "Because airport operation is a very critical operation. It involves many, many moving parts. So in <the Company>, we have the top management, which is the CEO and his direct reports. Like the CFO, the $\mathrm{COO}$, the head of planning, head of HR and so on". Document Source: Transcribed Voice Text (3:8).

- "Right now, I'm not to say this is code red or emergency situation because-yes, I do not have a ready successor - and that is worrying but the people supporting them is strong enough to cover them. Let's say, somebody leaves next week or crisis happen, the airport will not be at a standstill. But it is not ideal because I need to have a successor ready actually to take over, but I do not have a successor ready". Document Source: Transcribed Voice Text (3:27)

- "So we go through a process. We evaluate internal availability versus some resources externally. And from that pool, we will select those who are most eligible to fill up that position. But we never ignore internal candidates". Document Source: Transcribed Voice Text (3:11)

\section{Interpretative Meaning}

of LSP strategies

LSP current strategy practice is equipped with the ability to anticipate future trend based on previous performance. This is the only quotation this RQa code (refer to Error! Reference source not found.).

LSP current strategy practice have bases of assessment on technical competency and managerial competency. This is the only quotation this RQa code (refer to Error! Reference source not found.).

LSP current strategy practice follows structure. This is the only quotation this RQa code (refer to Error! Reference source not found.).

LSP current strategy practice does have interim solution for the fulfilment of candidate. This is the only interview quotation for this RQa code (refer to Error! Reference source not found.).

LSP current strategy practice goes through a process. There are 12 quotations from the interview and four LR statement for this RQa code (refer to Error! Reference source not found.). 


\section{Significant statement}

Interpretative Meaning

\section{Current Implementation of LSP strategies}

- "There is a first level selection amongst the management to short list candidates, namely me and the HR head. And then after that, we will recommend the candidates to the - what they call the - BNRC which is the Board Nomination Remuneration Committee. They will meet and they will interview those shortlisted candidates. And if they make the cut, they will go along with management recommendation. If they don't make the cut, in their point of view, they will start the process all over again". Document Source: Transcribed Voice Text (3:14).

- "Classic example is one of our rep in the C, Dato' Azmi. He will be retiring in about years' time. We've really identified three potential successors, and we are starting to train them. We are giving all the managerial development skill, coaching. We send coaches to them". Document Source: Transcribed Voice Text (3:29).

- "Who actually involved in this succession planning in term of planning and implementing it? HR. HR head". Document Source:

Transcribed Voice Text (3:33).

- "The model we have. The model very robust, very tight. But now - how to say it? - The process is there. The content it's not there yet". Document Source: Transcribed Voice Text (3:34).

- "But the candidate that makes the - what do you call it now, the definition? - R2, R3, R4 readiness level, okay, we have not fill up the boxes nicely because there are some people who are not ready yet". Document Source: Transcribed Voice Text (3:35). Also for code $R Q b$; Challenges to be effective.

- "As for the external search, it will be done by the company and a head hunter? And a head hunter. And a headhunter". Document Source: Transcribed Voice Text (3:38).

- "If very, very senior management, like top, top management, means direct report to the CEO, mainly head hunter. But if it's a senior manager level, it's mixed. Some head hunter, some internal". Document Source: Transcribed Voice Text (3:39)

- "Why you rely on the head hunter? Because the internal candidates are not ready. Because our succession planning process is not robust enough to make them ready". Document Source: Transcribed Voice Text (3:40). Also for Code RQb; Challenges to be effective. 


\section{Significant statement}

Interpretative Meaning

\section{Current Implementation of LSP strategies}

- "Both. Because whenever we put a candidate in for evaluation, there always will be an internal candidate or two, right? And, see, when you do an evaluation, you do two. You do an interview evaluation and a psychometric test evaluation". Document Source: Transcribed Voice Text (3:41)

- "Although we know the internet candidates may not be ready, he still go through the process of interview as well as a psychometric test. The psychometric test is like a leadership-style test, whether you are a situation leader, you are a task leader, people person leader because even if he doesn't make the cut yet, at least from the psychometric test, he knows where to improve himself to make himself ready. The test itself would show whether he is ready or not to go for the- what do you call it? Development. Development. Even if he's not ready now, at least his development plan is more clearly charted out from that result". Document Source:

Transcribed Voice Text (3:42).

- To identify and to develop high potential internal employees as an integral tasks of organizational planning and performance (Risher, 2015; Yamkovenko \& Hatala, 2015). Document Source: Literature Review

- Competencies and skills of highly potential managers need to be assessed accordingly and continuously, serve as critical components of LSP process (Moradi, 2014; Hanson, 2013). Document Source: Literature Review

- Having list of internal candidates from time to time for the talent pipeline creates good business sense. Top management should be willing to invest in application and synergistic practices for sourcing high potential internal talent through LSP, as social exchange does contribute towards this purpose.(Saratun, 2016) (Cho \& Poister, 2014). Document Source: Literature Review

- To another winning culture that benefits the organization and these high-potential employees can be generated via a cultivating replacement planning strategy (Sheth, 2016) (Nold, 2016). Document Source: Literature Review (also for RQb; Attitude and traits)

- "Since I just took over about three months back, and before that also, I think, for the seve months prior to that, so this is quite a new LSP current strategy practice does experience thinking from me. Previously, there isn't such a structured approach in this manner or that manner". Document Source: Transcribed Voice Text (3:16) 
Significant statement

Current Implementation of LSP strategies

- "So it is one example that- but if it's not that structure the every single position". Document Source: Transcribed Voice Text (3:30)

- "We are maybe ready for certain position, but other positions, we're not ready. So in short, our succession training process is not ideal yet". Document Source: Transcribed Voice Text (3:32)

- "And of course, down the line, he has many, many levels and each of the levels we have a readiness index to see whether you have successors ready to replace your position in two year time. And there are people ready in three year time and four year time and so on". Document Source: Transcribed Voice Text (3:9)

LSP current strategy practice uses readiness index for next 3 years and above in advance. There is one quotation from the interview for this RQa code (refer to Error! Reference source not found.).

\section{Theme: Tension between reality and applications}

Quotations from the interview in this sub-section are responding to the Research Question: Why there are gap between the expectation and the outcome of LSP, and how effective is it? What does the literature express on succession planning? What are the issues or variables that are important determinants of effective implementation of LSP initiatives? Each selected quotation or statement is linked to the research objectives as elaborated in the Interpretive Meaning column in Table 3 below.

TABLE 3: Significant Statement and Meaning from Tension between Reality and Application Theme.

\begin{tabular}{|c|c|}
\hline Significant statement & Interpretative Meaning \\
\hline \multicolumn{2}{|c|}{ Tension between reality and application } \\
\hline $\begin{array}{l}\text { "We need to have a better attitude. It's like an } \\
\text { iceberg theory; the knowledge is the top side } \\
\text { of iceberg. Attitude is the bottom of the } \\
\text { iceberg. So your attitude can actually make a } \\
\text { difference although you may not enjoy some of } \\
\text { the macroeconomic factors which are beyond } \\
\text { our control like you mentioned". Document } \\
\text { Source: Transcribed Voice Text (3:25). }\end{array}$ & $\begin{array}{l}\text { Explaining element and importance to reduce } \\
\text { the gap between reality and application in term } \\
\text { of attitude and traits. There is three quotation } \\
\text { from the interview and two quotations from LR, } \\
\text { for this } R Q b \text { code (refer to Error! Reference } \\
\text { source not found.). }\end{array}$ \\
\hline \multicolumn{2}{|l|}{$\begin{array}{l}\text { - "Because I internalize the three Cs } \\
\text { subconsciously already". Document Source: } \\
\text { Transcribed Voice Text (3:45) }\end{array}$} \\
\hline $\begin{array}{l}\text { "But the one I cannot teach you, that one he } \\
\text { has to be a habit ready. Habit. But in order to } \\
\text { become habit, they must be exposed and so } \\
\text { on". Document Source: Transcribed Voice Text } \\
(3: 46) \text {. }\end{array}$ & \\
\hline
\end{tabular}


Significant statement
Interpretative Meaning

Tension between reality and application

- Another winning culture that benefits the organization and these high-potential employees can be generated via a cultivating replacement planning strategy. (Sheth, 2016) (Nold, 2016). Document Source: Literature Review. Also for code RQa; through a process.

- Stakeholders and top management must take note that leadership succession planning is very important due to the fact that their companies have committed, dedicated and high-functioning trustees who work toward great outcomes for the plan (Galagan, 2010; Bocatto, 2010) Calareso, 2013; Beheshtifar, 2012; Fink, 2011) (Brent, 2013). Document Source: Literature review.

- "A lot of things to be done. To me, in order for Explaining how the gap between reality and us to- I always benchmark or set against Changi because Changi is the best airport in the world in terms of both what you call the ASQ ranking which is Airport Service Quality as well as the Skytrax ranking, they are always number one. So we have to benchmark. So if you ask me whether how I rate Malaysia Airports against Changi, these $3 \mathrm{Cs}$ as example". Document Source: Transcribed Voice Text (3:20).

- "As an airport operator, we always strive to be Explaining how the gap between reality and better and better but we are somewhat to face Malaysian environment is a bit more challenging because in Changi you are able to collect a lot more airport tax for any traveler. In Changi, all international travelers anyway are taxed at SingD 47 or equivalent 140 ringgit Malaysia. For us, when we travel to Singapore we only pay 35 ringgit airport tax. They collect four times more airport tax than us. And because of that they are able to refurbish and redo and regenerate the terminal much more frequently, they have much more money for training and development to upscale for new products and so on. We want to get that as well but our environment is so regulated, difficult to increase airport tax. So it is not an airport to airport comparison. If you give me the same airport tax as Changi, of course, I can do it like Changi". Document Source: Transcribed Voice Text (3:22).

- "But the candidate that makes the - what do you call it now, the definition? - R2, R3, R4 readiness level, okay, we have not fill up the boxes nicely because there are some people who are not ready yet". Document Source: Transcribed Voice Text (3:35). Also for code $\mathrm{RQa}$; through a process. application could be reduced by having a benchmark for effectiveness of the business operation and service. There is one quotation from the interview for this RQa code (refer to Error! Reference source not found.). application could be reduced by overcoming the challenges to be effective. There are nine quotations from the interview and one excerpt from LR for this RQb code (refer to Error!

Reference source not found.). 
- "For example, the CFO and COO are the ideal example where, using the internal model of readiness, the internal candidate is not ready. And therefore, immediately, it triggers an external search". Document Source: Transcribed Voice Text (3:36).

- "So the structure has all that ready. You need to have that. But the boxes or the actual not fill up". Document Source: Transcribed Voice Text (3:37).

- "Why you rely on the head hunter? Because the internal candidates are not ready. Because our succession planning process is not robust enough to make them ready". Document Source: Transcribed Voice Text (3:28). Also for code RQa; through a process.

- "But in <the Company> is so regulated, you need to have a lot of your skill in stakeholder management". Document Source: Transcribed Voice Text (3:44). Also for RQc; Managerial competency.

- "I should handle a few people that can replace my direct reporting immediately, right? But not quite yet, which shows that our process is still process-oriented. I mean, but not enough content-oriented". Document Source: Transcribed Voice Text (3:47).

- "There's content but no right candidate to fill-in". Document Source: Transcribed Voice Text (3:48).

- "Some other airports are also facing the same situation where the design capacity is now been overtaken by the actual capacity. And therefore we need to expand the airport. As we expand the airport naturally, the need for manpower and for succession planning becomes even more critical". Document Source: Transcribed Voice Text (3:49).

- "Because of them have not even heard of the Explaining how the gap between reality and three Cs. I'm the one who introduced three Cs. So to answer your question, no. I don't think it is so robust yet, this application". Document Source: Transcribed Voice Text (3:18)..

application could exist if the Company is unprepared to have the skills in competitive competencies. There is one quotation from the interview and one from LR, for this RQb code (refer to Error! Reference source not found.).

- The behavior of constant communication between leaders and high-potential employees linked and drives to the business needs affect its efficiencies and effectiveness, leads towards win-win workplace climate.(Metcalfe \& Metcalfe, 2013)(Stumpf, JR, Ehr, \& Dam, 2016; Blattner, 2015; Quintana, 2014)". Document Source:

Literature review. 
Significant statement

Interpretative Meaning

Tension between reality and application

- "I believed, every single position, we need to follow that structure. Then it's more organized". Document Source: Transcribed Voice Text (3:31).

- "Positive". Document Source: Transcribed Voice Text (3:19).

- "And then, right now there's still a lot of silos going on and therefore we don't harness the best ability amongst team dynamics. You can have every individual brilliance but you do not enjoy the team dynamics". Document Source: Transcribed Voice Text (3:24).

- Remediation of their learning gaps via new skills exposure and development, improves performance where they will become more promotable employees thus creating a win-win culture for the company and cultivating leadership skills makes employees from degrees of potential to emerge and shape as leaders (Jing \& Avery, 2016). Document Source: Literature review

- "So we have to be more united. When I say more united, I don't know if it is connected with succession planning but we cannot have too much silo mentality. We need to work more as a team". Document Source: Transcribed Voice Text (3:23)

- But we have still not harnessed the best potential that we can achieve shift together as a team". Document Source: Transcribed Voice Text (3:26)
Explaining how the gap between reality and application could be reduced if the Company follow the current structure of LSP. There is one quotation from the interview for this RQb code (refer to Error! Reference source not found.).

Explaining progress of LSP program in reducing the gap between reality and application. There is one quotation from the interview for this $R Q b$ code (refer to Error! Reference source not found.).

Explaining shortcoming in the team dynamics, in reducing the gap between reality and application. There is one quotation from the interview and one from LR, for this RQb code (refer to Error! Reference source not found.).
Explaining how to reduce the gap between reality and application of LSP by having to include teamwork. There are two quotations from the interview for this $R Q b$ code (refer to Error! Reference source not found.).

\section{Theme: Sustainability leadership.}

Quotations from the interview in this sub-section are responding to the Research Question: How succession planning will be able to prepare the next generation of CEO and general managers to be competent and able to function on the next higher level of management? What are the most important success factors that will have a positive effect on sustaining companies performance? Each selected quotation or statement is linked to the research objectives as elaborated in the Interpretive Meaning column in Table 4 below. 
TABLE 4: Significant Statement and Meaning from Sustainability Leadership Theme.

\section{Significant statement}

\section{Interpretative Meaning}

\section{Sustainability Leadership}

- "If I would embark three Cs- I will call it the three Cs. What are three Cs? Number one, in this future of work where things are getting more and more competitive, they need to have - to me - three Cs which are number one, critical problem-solving- critical thinking, sorry, critical thinking skills, means higher order thinking skills. Number two, the ability to solve complex problems. So complex problem-solving skill, the second $\mathrm{C}$. And the third $C$ is what I call a competitive culture. It means you need to have a competitive attitude. So these are some of- apart from the usual technical skill, I would assess the candidate on these three attributes." Document Source: Transcribed Voice Text (3:15).

- "So I'm actually now only starting to embark this training and development programs in order to sharpen the three Cs". Document Source: Transcribed Voice Text (3:17).

- "Long, long, long way to go. So that's why l'm Explaining how LSP can be effective through trying to develop the programs whether using development tool as to ensure sustainability external help or in-house in order to bridge that leadership. There are two quotations from the gap". Document Source: Transcribed Voice Text interview for this RQc code (refer to Error! (3:21). Reference source not found.) competitive competencies tool as to ensure sustainability leadership. There are two quotations from the interview for this RQc code (refer to Error! Reference source not found.).
Explaining how LSP can be effective through

- "Personally, my view, no because the scope enters beyond your competency skill but also a lot on stakeholder management in terms of managing various ministries. And, somehow, maybe in a way I am also, in a way, I should do my part more by bringing them along with me so that I can be sort of training them, coaching them". Document Source: Transcribed Voice Text (3:43).

- "As for coaching style in meeting organizational needs, it is important for the top management to leverage it to motivate and develop future leaders, and executive coaching is one of the most effective method for developing high potential internal managers for multiple job levels and promotions (Chung, 2012)". Document Source: Literature review (4:3).

- Rate of change and external influences are unpredictable, urging the need for organizational agility that influence internal operation disruption (Bass, 2008; Ariss, Cascio, \& Paauwe, 2014) (Jantti \& Greenhalgh, 2012). Document Source: Literature review (4:4)
Explaining how LSP can be effective through competitive competencies tool as to ensure sustainability leadership. There are four quotations from LR for this RQc code (refer to Error! Reference source not found.). 


\section{Sustainability Leadership}

- Fostering relationship building while addressing development gaps and improving connection between performance and potential, can be developed during one-to-one session, as a transactional exchange of information between the top management and those high potential employees (Allio, 2012). Document Source: Transcribed Voice Text (4:8).

- Leadership gaps is also addressed through the bi-directional relationship between them and top management, as they are to be accountable for sharpening, training and development of qualified high-potential managers though succession planning. (Saratun, 2016)(Stewart, 2016) (Quintana, 2014) (Dewah \& Mutula, 2014) (Blattner, 2015) (Moradi, 2014). Document Source: Transcribed Voice Text (3:10).

- So when we assess a candidate, we have two Explaining how LSP can be effective through bases of assessment. One is the technical competency and the other one is the managerial competency". Document Source: Transcribed Voice Text (3:12). Also for Code $\mathrm{RQa}$; bases of assessment. managerial Competency as to ensure sustainability leadership. There are three quotations from the interview for this $R Q c$ code (refer to Error! Reference source not found.).

- "Managerial competency talks about leadership, problem-solving skills, commercial orientation, and so on". Document Source: Transcribed Voice Text (3:13)

- "But in <the company> is so regulated, you need to have a lot of your skill in stakeholder management". Document Source: Transcribed Voice Text (3:44). Also for Code RQb; Challenges to be effective.

- The Malaysian Government has created and has a direct controlling stake in GLCs and the companies have a primary commercial objective. Document Source: Literature review (4:13).

- We recorded much-improved passenger traffic performance and therefore that resulted in us earning a great profitability and we

Explaining how LSP can be effective through managerial Competency as to ensure sustainability leadership. There is one quotation from LR for this RQc code (refer to Error! Reference source not found.).

The Need for LSP Explaining clearly the needs for LSP as to ensure sustainability leadership. There are two quotations from the interview for anticipate this trend to continue in the next few this RQc code (refer to Error! Reference source years". Document Source: Transcribed Voice not found.). Text (3:50).

- "As we expand the airport naturally, the need for manpower and for succession planning becomes even more critical". Document Source: Transcribed Voice Text (3:51). 


\section{References}

[1] Allio, R. J. (2012). Leaders and leadership - many theories, but what advice is reliable? Strategy \& Leadership, 41(1), 4-14. https://doi.org/10.1108/10878571311290016

[2] Ariss, A. a., Cascio, W., \& Paauwe, J. (2014). Talent management: Current theories and future research directions. Journal of World Business, pp. 173-179.

[3] Avey, J. B., Avolio, B. J., \& Luthans, F. (2011). Experimentally analysing the impact of leader positivity on follower positivity and performance. Leadership Quarterly, 22(2), 282-294.

[4] Bass, B. M. (2008). The Bass Handbook of Leadership: Theory, Research, and Managerial Applications, 4th Ed. New York, NY: Free Press.

[5] Beh. (2007). China International Conference "Implications of a Transforming China: Domestic, Regional and Global Impacts: International China World Conference, 1-36.

[6] Beheshtifar, M. \&.-P. (2012). Leadership Development Activities. International Journal of Academic Research in Business and Social Sciences Vol. 2, No. 7, 387-393.

[7] Bhawna, \& Gobind, \&. (2015). Research Methodology and Approaches. IOSR Journal of Research \& Method in Education (IOSR-JRME), 5(3), 48-51.

[8] Blattner \& Walter, J. -T. (2015). Creating and sustaining a highly engaged company culture in a multigenerational workplace. Strategic HR Review, 124-130.

[9] Bocatto, E. \&. (2010). Family-Owned Business Succession: The Influence of Preperformance in the Nomination of Family and Nonfamily Members: Evidence from Spanish Firms. Journal of Small Business Management, 48, 497-523.

[10] Bradley, E. H., Curry, L. A., \& Devers, K. J. (2007). Qualitative Data Analysis for Health Services Research: Developing Taxonomy, Themes, and Theory. Health Services Research v42(4), 1758-72.

[11] Brent, C. (2013). Succession Planning: Be proactive, not reactive. United Kingdom:: Ray and Berndtson Publishing.

[12] Calareso, J. P. (2013). Succession planning. The key to ensuring leadership. Planning For Higher Education, 41(3), 27-33.

[13] Carmeli, A., Schaubroeck, J., \& Tishler, A. (2011). How CEO empowering leadership shapes top management team processes: Implications for firm performance. Leadership Quarterly, 22(2), 399-411.

[14] Centre for Public Policy Studies. (2006, January 5). CPPS Recommendations for the 9th Malaysia Plan: Overview and Details. Centre for Public Policy Studies.

[15] Cho, Y. J., \& Poister, T. H. (2014). Managerial Practices, Trust in Leadership, and Performance. Public Personnel Management vol. 43, 179-196. 
[16] Chung, X. R.-N. (2012). Leadership succession and firm performance in an emerging economy: Successor origin, relational embeddedness, and legitimacy. Strategic Management Journal vol 34, 338-357.

[17] Dewah, P., \& Mutula, S. M. (2014). Knowledge retention strategies in public sector organizations: Current status in sub-Saharan Africa. Information Development., 1-15.

[18] Fink, D. (2011). Pipelines, pools and reservoirs: building leadership capacity for sustained improvement. Journal of Educational Administration, 49(6), 670-684.

[19] Galagan, P. (2010). Bridging the Skills Gap: New Factors Compound the Growing Skills Shortage. American Society for Training \& Development.

[20] García-Morales, V. J., Jiménez-Barrionuevo, M. M., \& Gutiérrez-Gutiérrez, L. (2012). Transformational leadership influence on organizational performance through organizational learning and innovation. Journal of Business Research, 65(7), 10401050.

[21] Greenhalgh, N., \& Jantti, M. (2012). Leadership competencies: a reference point for development and evaluation. Library Management, 33(6/7), 421-428.

[22] Hanson, B. (2013). The Leadership Development Interface: Aligning Leaders and Organizations towards More Effective Leadership Learning. Advances in Developing Human Resources, 15(1), 106-120.

[23] Haron, H., Khalid, S. N., Ganesan, Y., \& Fernando, Y. (2017). A Handbook For Business Research Methods pg 26-27. Kuala Lumpur: Pearson malaysia Sdn Bhd.

[24] Hayat, U. (2013). Malaysia's Khazanah: Not Just a SWF But a "Nation Building Institution". Kuala Lumpur: CFA Institute, url: https://blogs.cfainstitute.org/investor/ 2013/07/30/malaysias-khazanah-not-just-a-swf-but-a-nation-building-institution/.

[25] Horsburgh, D. (2003). Evaluation of qualitative research. Journal of Clinical Nursing v12(2), 307-312.

[26] Jing, F. F., \& Avery, G. C. (2016). Missing Links In Understanding The Relationship Between Leadership And Organizational Performance. International Business \& Economics Research Journal (IBER), 15(3), 107.

[27] Lewis, R. E., \& Heckman, R. J. (2006). Talent management: A critical review. Human Resource Management Review, 16(2), 139-154.

[28] Malaysia National Economic Advisory Council. (2008). NEW ECONOMIC MODEL Part l: Strategic Policy Directions, pg 54 \& pg 126. Kuala Lumpur: Percetakan Nasional Malaysia Berhad,

[29] Metcalfe, A., \& Metcalfe, A. (2013). Reliability and validity of the "leadership competencies and engaging leadership scale". International Journal of Public Sector Management, vol. 26, 56-73. 
[30] Mokhtar, A. (2005). The Malay way of business change. The Economist 376 (8440), p. 50 , August 18

[31] Moradi, M. R. (2014). Managers succession planning for human capital development. Advances in Environmental Biology, 8, 1776-1785.

[32] Neale, C. B. (2006). CONDUCTING IN-DEPTH - A Guide for Designing and. Watertown url: http://www2.pathfinder.org/site/DocServer/ m_e_tool_series_indepth_interviews.pdf: Pathfinder International Tool Series.

[33] Nold, H. (2016). The performance triangle: a model for corporate agility. Leadership \& Organization Development Journal, vol 3, 341-356.

[34] Pietrangelo, A. (2017, January 18). Left Brain vs. Right Brain: What Does This Mean for Me? Healthline news/etter, pp. https://www.healthline.com/health/left-brain-vsright-brain.

[35] Quintana, C. D. (2014). Competencies which shape leadership. International Journal of Manpower, Vol. 35 Issue: 4, 514-535.

[36] Rastogi, N., \& Trivedi, D. M.. (2016). Pestle Technique - a Tool To Identify External Risks in Construction Projects. International Research Journal of Engineering and Technology, 03(01), 384-388. Retrieved from www.irjet.net

[37] Risher, H. (2015). Employers Need to Invest to Strengthen Performance Management. Compensation \& Benefits Review, 47(2), 55-59.

[38] Rovai, A. P., Baker, J. D., \& Ponton, M. K. (2014). Social Science Research Design and Statistics: A Practitioner's Guide to Research Methods and SPSS Analysis. Virginia USA: Watertree Press LLC.

[39] Ryan, G. W., \& Bernard, H. R. (2003). Techniques to Identify Themes. Field Methods, v 15(1), 85-109.

[40] Saratun, M. (2016). Performance management to enhance employee engagement for corporate sustainability. Asia-Pacific Journal of Business Administration, Vol. 8 Issue: 1, 84-102.

[41] Sheth, M. (2016). How to achieve a win/win for both employees and corporates. Strategic HR Review, Vol. 15 Issue: 2, 70-75.

[42] Stumpf, S. A., JR, W. G., Ehr, R. J., \& Dam, N. H. (2016). Leading to intrinsically reward professionals for sustained engagement. Leadership \& Organization Development Journal, Vol. 37 Issue: 4, 467-486 Stephen A Stumpf, Walter G Tymon JR, Robert J Ehr, Nick HM van Dam.

[43] Stewart, C. (2016). How diverse is your pipeline? Developing the talent pipeline for women and black and ethnic minority employees. Industrial and Commercial Training, Vol. 48 Issue: 2, 61-66. 
[44] The SUN. (2017). Stringent Vetting Of GLC Heads. The SUN newspaper. Kuala Lumpur, Federal Territory, Malaysia: The SUN November 15

[45] Tracy, S. J. (2013). Qualitative Research Methods: Collecting Evidence, Crafting Analysis, Communicating Impact. Arizona State: Chichester: Wiley-Blackwell.

[46] Vietor, R. H. (2007). How Countries Compete: Strategy, Structure, and Government in the Global Economy. USA: Harvard Business School Press.

[47] Yamkovenko, B., \& Hatala, J. P. (2015). Methods for Analysis of Social Networks Data in HRD Research. Advances in Developing Human Resources, 17(1), 40-56.

[48] Zikmund, W. G., Carr, J. C., \& Griffin, M. (2013). Business Research Methods I 9th Edition. Boston, Massachusett: Cengaged. 